\title{
Mutation of ornithine transcarbamylase (H136R) in a girl with severe intermittent orotic aciduria but normal enzyme activity
}

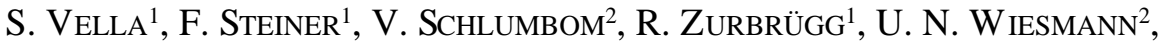 \\ T. SCHAFFNER ${ }^{3}$ and B. WERMUTH ${ }^{4 *}$ \\ ${ }^{1}$ Children's Hospital Wildermeth, Biel; Departments of ${ }^{2}$ Pediatrics, ${ }^{3}$ Pathology and \\ ${ }^{4}$ Clinical Chemistry, Inselspital, Berne, Switzerland \\ * Correspondence: Department of Clinical Chemistry, Inselspital, CH-3010 Bern, \\ Switzerland
}

MS received 6.8.96 Accepted 25.9.96

\begin{abstract}
Summary: Ornithine transcarbamylase deficiency shows X-linked inheritance with partial dominant expression in carrier females. We studied a girl with intermittent severe orotic aciduria and mild hyperammonaemia despite apparently normal enzyme activity in the liver. Sequence analysis of all 10 exons of the ornithine transcarbamylase gene revealed a novel $\mathrm{A} \rightarrow \mathrm{G}$ exchange (A502G) in exon 5 which changes His-136 to arginine in the ornithine transcarbamylase protein. $K_{\mathrm{m}}$ values for carbamyl phosphate and ornithine determined in the patient's liver were comparable to those of wild-type enzyme but, unlike the wild-type enzyme, the mutant enzyme was unstable upon freezing and thawing. Electron microscopy revealed several giant mitochondria with paracrystalline inclusions. The results are compatible with the assumption that the mutant enzyme cannot form a functional complex with carbamyl phosphate synthetase and the ornithine carrier, resulting in decreased availability of substrates and diminished enzyme activity in vivo.
\end{abstract}

Ornithine transcarbamylase (OTC) (EC 2.1.3.3.) catalyses the condensation of carbamyl phosphate and ornithine to citrulline in the second step of the urea cycle (Brusilow and Horwich 1995). The OTC gene contains 10 exons coding for a precursor protein of 354 amino acids from which a 32-amino-acid leader peptide is cleaved off on import into the mitochondrion. OTC deficiency (McKusick 311250), the most common inborn error of ureagenesis, shows X-linked inheritance. Affected boys typically present with fatal hyperammonaemia in the neonatal period or, in cases with partial enzyme deficiency, with recurrent metabolic crises often followed by mental retardation. Moreover, OTC deficiency exhibits partial dominant expression with 15-20\% of carrier females becoming symptomatic, symptoms ranging from occasional vomiting and lethargy to seizures, coma and even death (Batshaw et al 1986). The variable clinical picture is thought to result from unequal inactivation of one of the two X-chromosomes during early embryonic development (Lyon 
1972), leading to a mosaic pattern of hepatocytes consisting of cells with normal and cells with deficient OTC activity (Ricciuti et al 1976). In heterozygous girls, ammonia that accumulates in the diseased cells can be metabolized in the adjacent normal cells. Only in very unfavourably lyonized girls may ammonia accumulation exceed the metabolizing capacity of the adjacent healthy cells. Accordingly, symptomatic females usually have residual enzyme activities below $50 \%$ of the lower reference limit.

We here report on a 6-year-old girl with a severe course of OTC deficiency despite apparently normal OTC activity in the liver.

\section{MATERIALS AND METHODS}

Liver specimens of about 100mg were obtained by surgery, and aliquots were fixed in 5\% phosphate-buffered glutaraldehyde for microscopic examination or stored at $-20^{\circ} \mathrm{C}$ for enzyme determination. OTC activity was determined in samples of about $20 \mathrm{mg}$ by following citrulline formation from carbamyl phosphate and ornithine (Raijman 1983). Ammonia was determined spectrophotometrically on the basis of NADPH consumption by the glutamate dehydrogenase-catalysed reductive amination of 2-oxoglutarate. The concentrations of urinary orotic acid and orotidine were determined by HPLC ion-exchange chromatography $(50 \mathrm{mmol} / \mathrm{L}$ formic acid to $100 \mathrm{mmol} / \mathrm{L}$ ammonium formate, $\mathrm{pH} 4.8)$ on a Nucleosil 5 SB column (Macherey Nagel) and spectrophotometric detection using a photodiode array detector (Applied Biosystems).

Genomic DNA was isolated from peripheral blood leukocytes using proteinase $\mathrm{K}$, sodium dodecyl sulphate treatment and phenol-chloroform extraction. All 10 exons of the OTC gene, including adjacent intron sequences, were amplified by PCR using pairs of primers (one of them biotinylated) designed from the published sequence of the OTC gene (Matsuura et al 1993). Amplifications were performed according to standard protocols. Single-stranded DNA was generated by using a streptavidin-based biomagnetic separation system (Dynal, Oslo, Norway), and both the free and immobilized single strands were sequenced by the dideoxy chain termination method using Sequenase 2.0 and $\left[\alpha-{ }^{35}\right.$ S $]$ dATP (Amersham).

\section{CASE REPORT}

A hitherto healthy 14-month-old girl of unrelated parents of Spanish-Italian origin was admitted to the hospital because of recurrent vomiting after returning from a holiday in Spain. On examination, the only clinical symptom was a painful liver, which was enlarged $4 \mathrm{~cm}$ below the costal margin. Laboratory investigations revealed hyperammonaemia $(235 \mu \mathrm{mol} / \mathrm{L})$, markedly elevated serum transaminases (ASAT $2900 \mathrm{IU} / \mathrm{L}$, ALAT 1900IU/L), and a decreased PTT (15\%). Screening for antibodies against hepatitis A, B and C, cytomegalovirus and Epstein-Barr virus, toxoplasmosis and leptospirosis was negative. Further tests excluded Wilson disease, $\alpha_{1}$-antitrypsin deficiency, cystic fibrosis and fructose intolerance. Finally, screening for urinary organic acids revealed large amounts of orotic acid (1900 mmol/mol creatinine), and the diagnosis of OTC deficiency was made. A diet poor in protein $(0.8 \mathrm{~g} / \mathrm{kg}$ body weight $)$ with substitution of essential amino acids, citrulline and carnitine was introduced. Within a few days, clinical symptoms and the abnormal laboratory findings returned to normal. Subsequently, the patient suffered from recurrent episodes of marked orotic aciduria and mild hyperammonaemia (Figure 1), which were often but not 

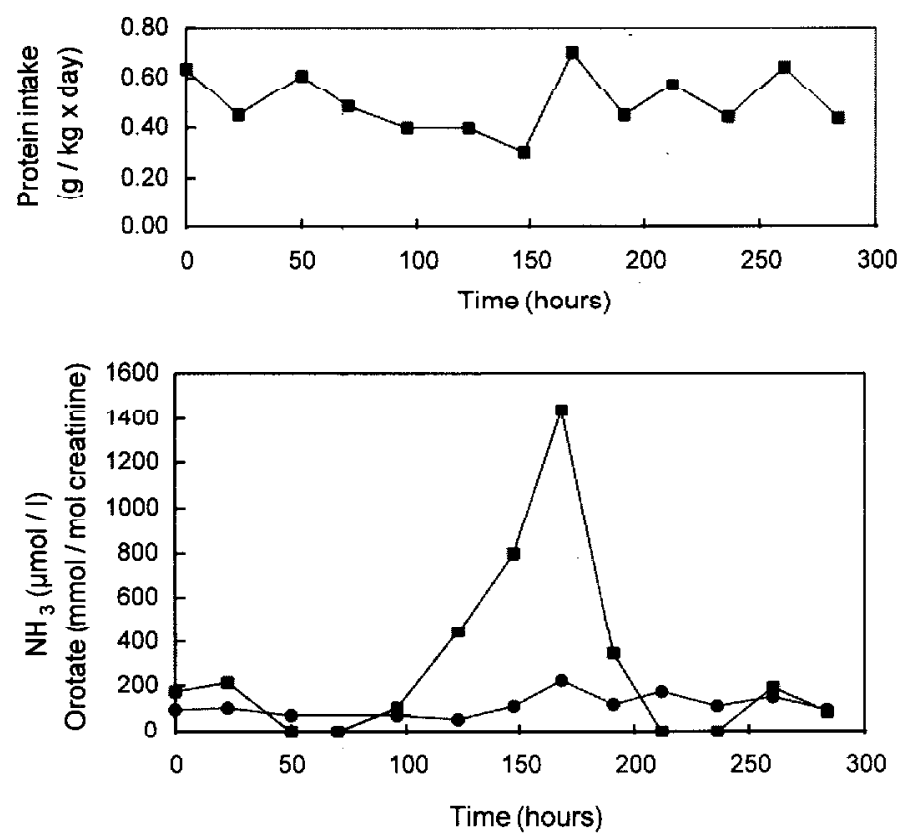

Figure 1 Protein intake (upper panel) and urinary orotic acid ( $\mathbf{(})$ and plasma ammonia concentrations (lower panel) in a girl with ornithine transcarbamylase deficiency. The protein intake corresponds to natural protein. In addition, the patient obtained $0.8 \mathrm{~g}$ essential amino acids (UCD 2, Milupa) per $\mathrm{kg}$ body weight per day

always precipitated by minor health impairments. Since protein restriction did not prevent metabolic derangement, sodium benzoate was added to the diet, but did not abolish orotic aciduria. A loading test with allopurinol (Hauser et al 1990) yielded grossly elevated excretion of orotic acid $(2460 \mathrm{mmol} / \mathrm{mol}$ creatinine after $6 \mathrm{~h}$ ) as well as significantly increased orotidinc $(69 \mathrm{mmol} / \mathrm{mol}$ creatininc). In the patient's mother, the test was negative. Deter mination of OTC activity in a liver sample obtained by laparotomy at the age of 2 years surprisingly yielded a value in the normal range (Table 1). Light and electron microscopic examination of the liver tissue showed no abnormalities. Nevertheless, DNA analysis was carried out and revealed a single $A \rightarrow G$ exchange in exon 5 of the OTC gene (Figure 2), leading to an Arg for His substitution in the OTC protein. The mutation was not detectahle. in the parents or in a younger sister. A second laparotomy at the age of 4 years again yielded normal OTC activity in one piece and slightly reduced activity in another piece of the liver (lable 1). Light microscopy showed some isolated, densely granular hepatocytes and pale parenchymal areas as well as minor fibrotic changes. Electron microscopy revealed scattered polymorphic. enlarged mitochondria with paracrystalline inclusions consisting of bundles of parallel, electron-dense filaments (Figure 3). MRI of the brain carried out at the age of $5 \frac{1}{2}$ years showed no abnormalities. The patient, now aged 6 years, shows normal physical and mental development but still suffers fionn tecunent hyperammonaemia and orotic aciduria despite continuous protein restriction and sodium benzoate medication. 
Table 1 Activity and Michaelis constants of ornithine transcarbamylase in the liver of a patient with ornithine transcarbamylase deficiency and a control person

\begin{tabular}{lcccc}
\hline & First biopsy & \multicolumn{2}{c}{ Second biopsy } & Control liver \\
\cline { 3 - 3 } & & Sample 1 & Sample 2 & \\
\hline $\begin{array}{l}\text { Activity (IU/mg protein) } \\
\text { First freeze - thaw cycle }\end{array}$ & 0.22 & 0.23 & 0.09 & $0.18^{\mathrm{a}}$ \\
$\quad$ Second freeze-thaw cycle & 0.06 & 0.03 & 0.18 \\
$K_{\mathrm{m}}$ carbamyl phosphate ${ }^{\mathrm{b}}(\mathrm{mmol} / \mathrm{L})$ & 0.39 & 0.57 & 0.34 \\
$K_{\mathrm{m}}$ ornithine $^{\mathrm{c}}(\mathrm{mmol} / \mathrm{L})$ & 0.33 & 0.16 & 0.63 \\
\hline
\end{tabular}

Enzyme activity was determined in $270 \mathrm{mmol} / \mathrm{L}$ triethanolamine $-\mathrm{HCl}$ (pH 7.7), containing $5 \mathrm{mmol} / \mathrm{L}$ carbamyl phosphate and $2.5 \mathrm{mmol} / \mathrm{L}$ L-ornithine, at $37^{\circ} \mathrm{C}$. $K_{\mathrm{m}}$ values were calculated by non-linear regression from initialrate data using variable concentrations of one and fixed concentrations of the other substrate

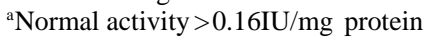

${ }^{\mathrm{b}}$ Ornithine $=5 \mathrm{mmol} / \mathrm{L}$

${ }^{\mathrm{c}}$ Carbamyl phosphate $=2 \mathrm{mmol} / \mathrm{L}$

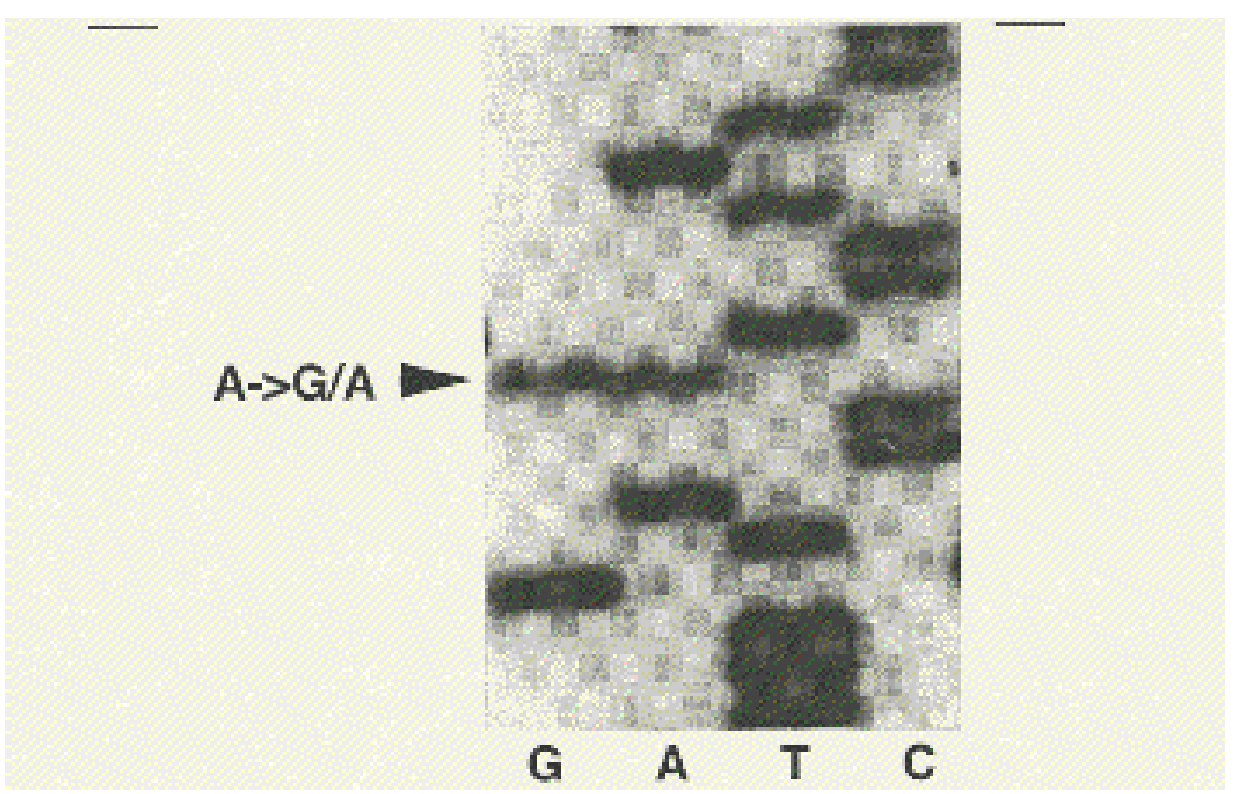

Figure 2 Partial DNA sequence of PCR-amplified exon 5 of the ornithine transcarbamylase gene from a girl with ornithine transcarbamylase deficiency. At position 503, both the wild-type adenine and the mutant guanine are detectable

\section{RESULTS AND DISCUSSION}

The salient feature of this case is the severe course of the disease in spite of apparently normal OTC activity in the patient's liver. In normal subjects, the activity of OTC in vitro exceeds the rate of ureagenesis more than 100-fold. Although in vivo substrate availability 


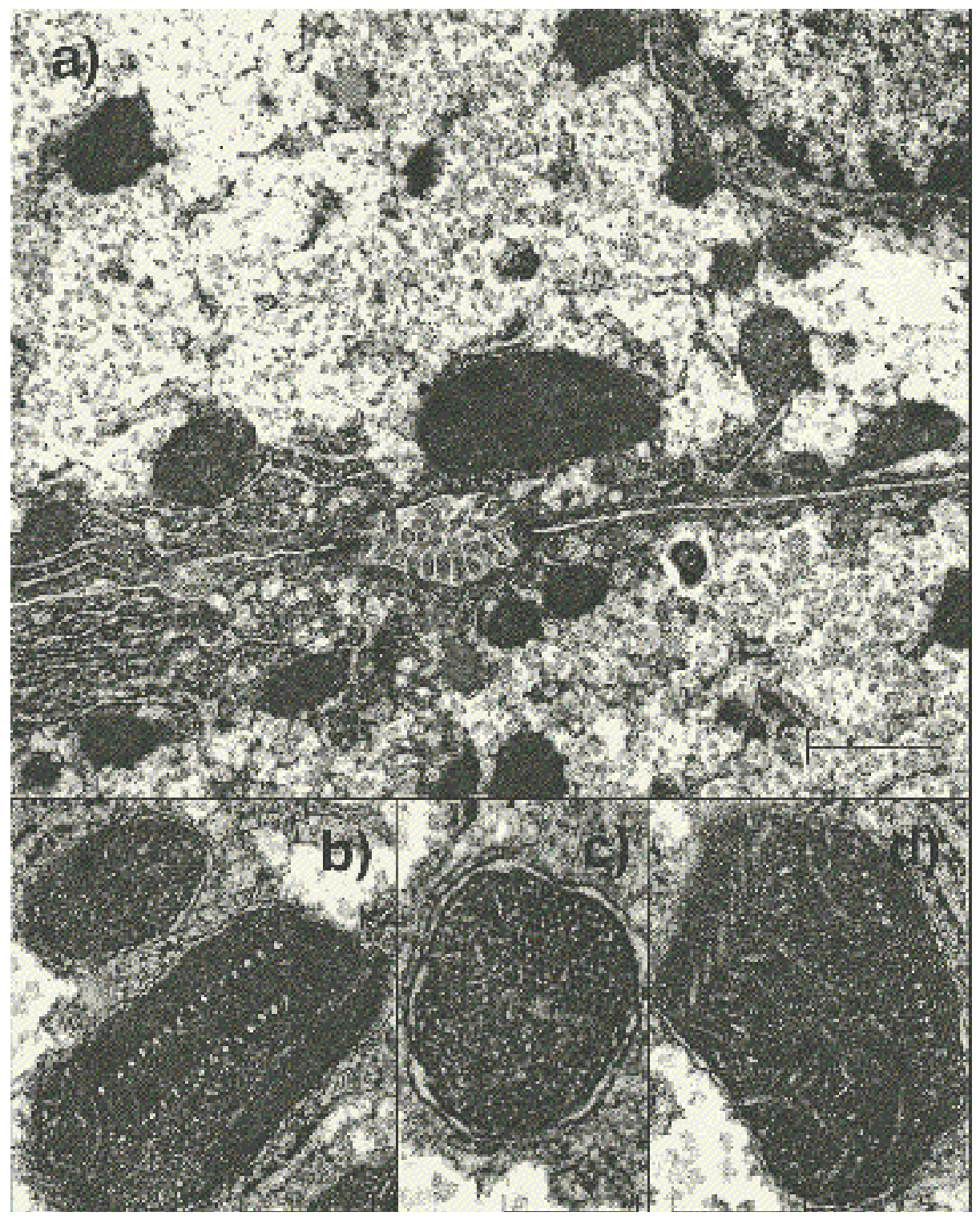

Figure 3 Electron micrograph of hepatocytes from a girl with ornithine transcarbamylase deficiency. Liver tissue was fixed in $5 \%$ glutaraldehyde followed by $1 \%$ osmium tetroxide in $0.1 \mathrm{~mol} / \mathrm{L}$ phosphate, $\mathrm{pH}$ 7.3, and embedded in Spurr's low viscosity resin. Thin sections were contrasted with uranyl acetate and lead citrate. Adjacent to extended smooth endoplasmic reticulum, giant mitochondria with electron-dense inclusions are seen around the bile canaliculus (a). In (b)-(d), higher magnification of the electron-dense material reveals paracrystalloid inclusions cut longitudinally (b) appearing as filaments, transversely (c) with an apparent diamond-shaped profile, and at an oblique angle (d) with a herring-bone intercrystalloid pattern. The periodicity of the filaments is about $190 \mathrm{~nm}$. Bars correspond to $2 \mu \mathrm{m}$ in (a), $0.5 \mu \mathrm{m}$ in (b,d) and $0.25 \mu \mathrm{m}$ (c) 
limits the enzyme activity, OTC deficiency usually becomes manifest only in patients with significantly reduced enzyme activity. Several boys have been described with less than $10 \%$ residual enzyme activity who showed no symptoms of OTC deficiency for many years (Tuchman et al 1992; Matsuura et al 1993; Oppliger Leibundgut et al 1995a). The residual activity at which OTC deficiency becomes manifest is expected to be even lower in females, in whom substrates which accumulate in the diseased hepatocytes can be removed, at least in part, by the surrounding healthy cells. We can, therefore, conclude that in the present case the enzyme activity determined in vitro does not reflect the activity in vivo.

One reason for this discrepancy might be a sampling error due to the mosaic pattern of healthy and affected cells (Ricciuti et al 1976). Evidence against this possibility comes from the observation that OTC activity in the liver from our patient was less stable upon freezing and thawing than the enzyme from a control person. Thus, when we repeated the determination of enzyme activity in the two samples from the second laparotomy after an additional cycle of freezing and thawing, it had dropped to $26 \%$ and $33 \%$, respectively, of the original value. Freezing has been shown to preserve OTC activity in normal liver over long periods, and repeated thawing usually does not markedly affect enzyme activity. In fact, in the control liver, OTC activity remained essentially unchanged after the second thawing and was still above $85 \%$ after two additional cycles of freezing and thawing. Hence, at least $65-75 \%$ of the activity in the biopsy material appears to result from the mutant, more labile enzyme, a proportion that may even be higher considering that the tissue had already been frozen before the first determination of enzyme activity.

Further evidence against a sampling artefact comes from work by Tuchman (1993), who showed that OTC activity varied at most by $\pm 15 \%$ in 10 samples of about $20 \mathrm{mg}$ (the amount used in our study) taken from the livers of two females heterozygous for OTC deficiency. Other factors than the uneven distribution of healthy and diseased cells must therefore be responsible for the apparently different activities in vivo and in vitro.

DNA analysis had revealed a single $A \rightarrow G$ exchange $(A 502 G)$ in exon 5 of the OTC gene (Figure 2) which changes His-136 in the mature OTC protein (His-168 in the precursor protein) to arginine. No other mutation was detected by complete sequencing of the remaining 9 exons, including the first nucleotides of the adjoining introns. The absence of additional mutations in our patient and of the A502G mutation in the patient's mother strongly suggests that the H136R mutation is responsible for the altered properties of the protein. The histidine is completely conserved among 26 OTC sequences from vertebrates, yeasts and bacteria, and computer modelling based on the three-dimensional structure of E. coli aspartate transcarbamylase positions it in the active centre where it is thought to participate in carbamyl phosphate binding (Tuchman et al 1995). Replacement by arginine might thus increase the $K_{\mathrm{m}}$ value for carbamyl phosphate. This, in turn, would decrease the enzymatic activity under physiological conditions when substrates are limiting but have little effect under the conditions of substrate saturation in vitro. Michaelis constants for both substrates, carbamyl phosphate and ornithine, were therefore determined in the two liver samples from the second laparotomy. As shown in Table $1, K_{\mathrm{m}}$ values for carbamyl phosphate were not significantly different in the two samples from the patient and a control liver, respectively. $K_{\mathrm{m}}$ values for ornithine appeared to be somewhat lower for the mutant enzyme. However, owing to the limited amount of liver tissue, Michaelis constants were 
calculated from measurements at only four substrate concentrations, and the numbers in Table 1 should be considered as approximations. Moreover, they are a mixture of the values from both the normal and mutant enzymes. Nevertheless, the experimentally determined $K_{\mathrm{m}}$ values do not seem to explain the discrepancy between the enzyme activity in vitro and in vivo.

For further explanation, we may assume that the kinetic properties of the mutant and native enzymes are indeed not markedly different but that, unlike in the homogenate, the access of substrate(s) to the active site of the enzyme is limited in the mitochondrial matrix. Cohen and coworkers (1987) have presented convincing evidence of channelling of extramitochondrial ornithine to OTC in the mitochondrial matrix and postulated that the enzyme is juxtaposed to the inner face of the inner mitochondrial membrane in close proximity to the ornithine transporter and carbamyl phosphate synthetase. If the mutant enzyme cannot form this complex, substrate availability might become limited, resulting in functional OTC deficiency.

Although we have no proof of this hypothesis an indication that the enzyme may indeed be in a nonfunctional position in the mitochondrial matrix comes from the electron microscopic examination of the liver biopsy material, which revealed several enlarged mitochondria with paracrystalline inclusions. Mitochondrial crystalloids occur in a variety of disorders, including OTC deficiency (Tallan et al 1983), and have recently been associated with intramitochondrial protein accumulation, e.g. creatine kinase in mitochondrial myopathy (Stadhouders et al 1994). Although OTC protein has not yet been identified in mitochondrial inclusion bodies, its concentration has been shown to increase in OTC deficiency, probably as compensation for the reduced activity (Zimmer et al 1995). It thus seems feasible that, in the mitochondria of our patient, enzymatically active but physiologically non-functional OTC accumulates and finally aggregates to the paracrystalline structures. The formation of ordered aggregates which may stabilize the protein structure could also explain the enzyme's susceptibility to freezing and thawing, which may cause the aggregates to fall apart with a concomitant destabilization of the enzyme.

We have recently been able to express mature, enzymatically active OTC in E. coli (Oppliger Leibundgut et al 1995b). Using the same technique we will try to express the mutant enzyme in sufficient quantities to allow us to study its properties in more detail and to test our hypothesis.

\section{REFERENCES}

Batshaw ML, Msall M, Beaudet AL, Trojak J (1986) Risk of serious illness in heterozygotes for ornithine transcarbamylase deficiency. J Pediatr 108: 236-241.

Brusilow SW, Horwich AL (1995) Urea cycle enzymes. In Scriver CR, Beaudet AL, Sly WS, Valle D, eds. The Metabolic and Molecular Bases of Inherited Disease, 7th edn. New York: McGrawHill, 1187-1232.

Cohen NS, Cheung C-W, Raijman L (1987) Channeling of extramitochondrial ornithine to matrix ornithine transcarbamylase. J Biol Chem 262: 203-208.

Hauser ER, Finkelstein JE, Valle D, Brusilow SW (1990) Allopurinol-induced orotidinuria: a test for mutations at the ornithine carbamoyltransferase locus in women. N Engl J Med 322: 1641-1645.

Lyon MF (1972) X-chromosome inactivation and developmental patterns in mammals. Biol Rev 47: $1-35$.

Matsuura T, Hoshide R, Setoyama C, et al (1993) Four novel gene mutations in five Japanese male patients with neonatal or late onset OTC deficiency: application of PCR-single-strand conformation polymorphisms for all exons and adjacent introns. Hum Genet 92: 49-56. 
Oppliger Leibundgut E, Liechti-Gallati S, Colombo J-P, Wermuth B (1995a) Ornithine transcarbamylase deficiency: new sites with increased probability of mutation. Hum Genet 95: 191-196.

Oppliger Leibundgut E, Liechti-Gallati S, Wermuth B (1995b) Expression of ornithine transcarbamylase in E. coli. Experientia 51: A9.

Raijman L (1983) Ornithine carbamoyltransferase measurement in liver. In Bergmeyer HU, ed. Methods of Enzymatic Analysis, 3rd edn. Weinheim: Verlag Chemie, 326-334.

Ricciuti FC, Gelehrter TD, Rosenberg LE (1976) X-chromosome inactivation in human liver: confirmation of X-linkage of ornithine transcarbamylase. Am J Hum Genet 28: 332-338.

Stadhouders AM, Jap PH, Winkler HP, Eppenberger HM, Wallimann T (1994) Mitochondrial creatine kinase: a major constituent of pathological inclusions seen in mitochondrial myopathies. Proc Natl Acad Sci USA 91: 5089-5093.

Tallan HH, Schaffner F, Taffet SL, Schneidman K, Gaull GE (1983) Ornithine carbamoyltransferase deficiency in an adult male patient: significance of hepatic ultrastructure in clinical diagnosis. Pediatrics 71: 224-232.

Tuchman M (1993) The clinical, biochemical and molecular spectrum of ornithine transcarbamylase deficiency. J Lab Clin Med 120: 836-850.

Tuchman M, Holzknecht RA, Gueron AB, Berry SA, Tsai MY (1992) Six new mutations in the ornithine transcarbamylase gene detected by single-strand conformational polymorphism. Pediatr Res 32: 600-604.

Tuchman M, Morizono H, Reish O, Yuan X, Allewell NM (1995) The molecular basis of ornithine transcarbamylase deficiency: modelling the human enzyme and the effects of mutations. J Med Genet 32: 680-688.

Zimmer K-P, Matsuda I, Matsuura T, et al (1995) Ultrastructural, immunocytochemical and stereological investigation of hepatocytes in a patient with the mutation of the ornithine transcarbamylase gene. Eur J Cell Biol 67: 73 -83. 